\title{
Measuring the Impact of Public Expenditure on Economic Growth in Nigeria
}

\author{
Ogunmuyiwa Michael Segun (Corresponding Author) \\ Department of Economics, Olabisi Onabanjo University, Ogun State, Nigeria \\ E-mail: misego@yahoo.com Tel: 234-805-543-0044
}

Adelowokan, O. A.

Department of Economics, Olabisi Onabanjo University, Ogun State, Nigeria

E-mail: seyiadelowokan@gmail.com Tel: 234-805-259-4056

Received: May 14, 2014 Accepted: February 11, 2015 Published: March 1, 2015

doi:10.5296/jsss.v2i2.5626 URL: http://dx.doi.org/10.5296/jsss.v2i2.5626

\begin{abstract}
This paper investigates the impact of public expenditure on economic growth in Nigeria. In an attempt to do this time series data from 1970 to 2008 were fitted into the regression equation using various econometric techniques such as Augmented Dickey Fuller (ADF) unit root test, the Johansen co-integration technique and the Box-Jekins O. L. S. methodology. Empirical results affirmed that public expenditure has a positive and significant impact on economic growth in Nigeria. Public current expenditure was also found to exhibit a positive impact on growth at 10 percent significance level. While public capital expenditure albeit insignificant but showed a positive impact of growth. The study concludes that government should as a matter of policy invest heavily in public infrastructures to usher in the desired growth and development in the country.
\end{abstract}

Keywords: Current expenditure, Capital expenditure, Economic growth

\section{Introduction}

The study of the dynamic relationship that exists between public expenditure and economic growth is very salient in policy-making for governments across the world especially those of Less Developing Countries -LDCs. The size of public expenditure and its effects on the long-run economic growth and vice-versa has been an issue of sustained interest for decades by economists. Thus, there have been various studies and an avalanche of literatures to 
support this assertion. The Wagner's Law has explored the principal causes of growth in the public sector. Following this law, increasing expansion of public and particularly state activities is one of the earliest attempts made that emphasized economic growth as the fundamental determinant of public sector growth. Empirical tests of this hypothesis have yielded results that differ considerably from country to country. The size of public sector and its impact on economic growth has emerged as a major public choice issue facing economies in transition. The question of the size of government has traditionally been divided between two extremes.

The first argues that larger government is typically detrimental to efficiency, productivity and growth. This was predicated on the basis that the public sector is not responsive to market signal; an onerous regulatory process that engenders higher production costs; and distortions that arise from both fiscal and monetary policies. The other school articulates in favor of larger government role in the economy. It articulates the need for provision of certain goods and services that would otherwise not be provided by the private sector, in order to place the economy on a predetermined growth path.

Empirical evidence on the relationship between public expenditure and growth is diverse and controversial. Most studies show that recurrent government spending has the negative impact on growth but on the other hand, some studies have shown that government spending has a positive impact on economic growth (i.e. the provision of social and physical infrastructure through public investment and disbursement on some goods and services is theoretically believed to be able to increase productivity in the private sector through the more efficient allocation of resources). The unending controversy as to the relationship between public expenditure and economic growth has brought about the continued research into this field.

With respect to Nigeria, the public sector expanded rapidly in the post-independence era, following the massive intervention of government in various aspects of economic activities. In the absence of robust private sector, the Nigerian government on attainment of political independence, assumed the role of a prime mover of the economy. The public sector then become a channel through which government could deliver social services and goods, provide socio-economic infrastructure, expand the rate of industrialization and create employment opportunities. This perceived role of the public sector in the growth and development process according to (Adubi \& Obioma, 1995) led to the tremendous growth in public expenditure. The main questions which this study intends to address include: what is the size and composition of public expenditure in Nigeria? What is the relationship between public expenditure and the growth of real GDP in Nigeria? What are the relative contributions of various components of total public expenditure (recurrent and capital) to economic growth in Nigeria? 


\section{LiteratureReview and Theoretical Underpinnings}

\subsection{Review of Empirical Studies}

Buchanan and Tullock (1961) in the context of US experience Wagner's theory in terms of increasing discrepancy between growth of government expenditure and government output and termed the phenomenon as "Wagner Squared" hypothesis. They base their argument on two facts. Firstly, in contrast with the situation prevailing in the private sector, expenditure on civil servants grows faster than the corresponding increase in their output. Secondly, with increasing social security and other measures, the proportion of population receiving transfer payments from authorities keeps increasing. This way public expenditure increases both in absolute terms and as a proportion of national income.

Bhatia (1976) argued that on the face of it, Wiseman Peacock hypothesis looks quite convincing. But, we need to remember that they are emphasizing the recurrence of abnormal situations which cause sizeable jumps in public expenditure and revenue. In all fairness to the historical facts, we must not forget that on account of advancement of the economy and the structural changes therein, there are constant and regular increments in public expenditure and revenue. Public expenditure has a tendency to grow on account of a systematic expansion of the public activities. Increasing population, urbanization and an ever-increasing awareness of the civic rights on the part of the public, coupled with an increasing awareness by the state of its duties and responsibilities, often result in an upward movement of public expenditure. Public expenditure to a large extent is expected to be financed by increasing revenue which is made possible through the expansion and structural changes in the economy.

Wiseman and Peacock (1958) in their study of public expenditure in UK for the period 1890-1955 argued that public expenditure does not increase in a smooth and continuous manner, but in stepwise manner. At times, some social or other disturbances take place, leading to a need for increase public expenditure which the existing public revenue cannot meet.

Saunders and Klan (2002) made use of a "cost accounting" approach to analyze the growth of public expenditure in developed countries. They looked at government programmes including health, education and social security and then separated the effects of demographic influences, change in coverage, and increase in real benefit. Using pension expenditure as a case study, they attributed the growth to an expanding system of entitlement resulting from both demographic and broadened coverage. In the areas of health and education they found that the level of benefits has grown more than the number of beneficiaries. On human capital development, Adamu (2003) quoting Schultz (1961) identified five ways of developing human resources which are investment in health facilities; on-the-job training; formally organised education at the elementary, secondary and higher levels; study programme for adults that are not organized by firms, including extension programmes notably in agriculture; migration of individuals and families to adjust to changing job opportunities. Also, Lawal and Wahab (2011) while investigating the impact of education on economic growth using Nigerian data from confirmed that education investments have direct impact on economic growth in Nigeria. In addition, Deniz and Dugruel (2008), stressed that the well-educated human resources can also help facilitate the absorption of advanced technology. Junko and Vitali (2008) investigated the impact of public expenditure on economic growth in Azerbaijan 
because of the temporary oil production boom (2005-07), which caused exceptionally large expenditure increase aimed at improving infrastructure and rising incomes. Azerbaijan's total expenditure increased by a cumulative $160 \%$ in nominal value from 2005 to 2007 or from 41 percent of non-oil GDP to 74 percent oil GDP. In their research, references were made to Nigeria and Saudi Arabia (1970-89) who have also experienced oil boom and increased public expenditure over the years. The study simulated the neo-classical growth model tailored to the Azeri conditions. Their analysis suggested that the evaluated fiscal scenario possessed significant risks to growth sustainability and historical experience indicates that the initial growth performance largely depends on the efficiency of scale-up expenditure. The study also sheds light on the risks associated with a sudden cut in expenditure, including the political difficulties to undertake an orderly expenditure reduction strategy without undermining economic growth and the crowding-out effects of large government domestic borrowing. Also, Otu and Adenuga (2006) examine the relationship between economic growth and human capital development using Nigerian data from 1970 to 2003. They applied co-integration theory incorporating the error correction mechanism and found that investment in human capital, through the availability of infrastructural requirements in the education sector accelerates economic growth.

\subsection{Theoretical Framework}

For the purpose of investigating the relationship between public expenditure and economic growth in Nigeria, the Solow growth Model is used as the theoretical framework. The model maintained that output(Y) is determined by the amount of capital (K), labour (L), and "Knowledge" or the "effectiveness of labour"(A). At any time, the economy has some amounts of capital, labour, and knowledge and these are combined to produce output. The production function takes the form

$$
Y(t)=f[A(t) L(t), K(t)]
$$

In equation (1) above, time does not enter the function directly except through $\mathrm{K}, \mathrm{L}$ and $\mathrm{A}$. This implies that output changes over time only if the inputs to the production change. The amount of output obtained from given quantities of capital and labour rises overtime and technical progress occurs only if amount of knowledge increases. The critical assumption of the Solow model concerning the production function in equation (1) is that it has constant returns to scale in its two arguments, capital and effective labour. This means that doubling $\mathrm{K}$ and $\mathrm{L}$ with A doubles the amount produced. The second assumption is that other than capital, labour and knowledge are relatively unimportant. In particular, as put by (Romer, 1996) the model neglects land and other natural resources. If natural resources are important, doubling capital and labour could less than double output. This assumption is not too restrictive since, in practice, the availability of natural resources does not appear to be a major constraint on growth.

The intensive form of the production function in (1) can be expressed as:

$$
Y=k^{a}
$$

The explicit form of the Solow growth model is usually expressed as a Cobb-Douglas production function. Given the assumption of constant return to scale, the Cobb-Douglas production function can therefore be expressed as: 


$$
Y(t)=\{K(t)\}^{\alpha}\left\{A(t) L(K\}^{1-\beta}\right.
$$

Where $\mathrm{Y}, \mathrm{K}, \mathrm{A}$ and $\mathrm{L}$ are as previously defined. This model will be used in this study to investigate the impact of public expenditure on economic growth in Nigeria.

\section{Methodology and Empirical Findings}

\subsection{Model}

The use of a Solow model has been adopted for this study. This is because it is one of the most generally accepted models of economic growth. This model assumes that growth is influenced by the technical relationship between capital and labour. The flexibility which this model offers in the introduction of policy variables has made the model more popular in the analysis of growth of nations most especially in developing countries. This has led to the choice of the Solow model in this analysis.

Using the Solow Model, we specify that output is determined by the amount of capital and labour force in the economy. This assertion can be expressed as

$$
Y=A f(L, K)
$$

Since the Solow model is based on the Dobb-Douglas production model, we express it as

$$
Y=A K^{a} L^{b}
$$

Where A is efficiency parameter and (a) and (b) are assumed to be less than one, indicating the presence of diminishing returns to a single factor and $a+b=1$, indicating constant returns to scale.

To examine the impact of public expenditure on economic growth in Nigeria, we introduce a variable capturing public expenditure (PE) in Equation (5) and this yield Equation (6) below.

$$
Y=A K^{a} L^{b}(P E)^{l-a-b}
$$

For estimation purpose, we linearized equation (6) by taking its logarithm and introducing an error term (u.) This gives

$$
\log Y=\log (A)+a(\log ) K+b \log (L)+(1-a-b) \log (P E)+\mu
$$

Equation (7) above will be estimated in the following form

$$
\log (Y)=\beta_{0}+\beta_{1} \log (K)+\beta_{2} \log (L)+\beta_{3} \log (P E)+\mu
$$

The a-priori expectation for Equation (7) above is B1 $>0$; B2 $>0$; and B3 $><0$. The a-priori expectation implies that labour and capital are expected to affect real output positively, while public expenditure can have negative or positive impact on economic growth. To test the relative contributions of public current expenditure (PCE) and public capital expenditure (PCAE) to economic growth, we break total public expenditure into these two components and re-estimate Equation (7) as follows.

$$
\log (Y)=\beta_{0}+\beta_{1} \log (K)+\beta_{2} \log (L)+\beta_{3} \log (P C E)+\beta_{4} \log (P C A E)+\mu
$$

\subsection{Unit Root Test}

Before proceeding to estimating Equations (8)and (9), it is incumbent to determine the stationarity of the series as most time series data normally contain unit root and therefore not stationary. Regression with non stationary data most often produces spurious results and unreliable estimates. The Augmented Dickey Fuller (ADF) test result is presented in Table (1). 
Table 1. ADF Unit Root Test at levels and $1^{\text {st }}$ and $2^{\text {nd }}$ difference (1970-2008)

\begin{tabular}{llllllll}
\hline \multicolumn{2}{l}{ ADF Unit Root Test at Levels } & \multicolumn{5}{c}{ ADF Unit Root Test at $\mathbf{1}^{\text {st }}$ and $\mathbf{2}^{\text {nd }}$ Difference } \\
\hline Variables & ADF & Prob & Stationarity & ADF & Prob & Lag Length & Order of Integration \\
\hline Y & 1.811729 & 0.9996 & Not Stationary & 3.96887 & 0.0041 & 1 & I $(1)$ \\
K & 1.29036 & 0.6238 & Not Stationary & 3.19674 & 0.0283 & 1 & I $(1)$ \\
L & 0.381574 & 0.9794 & Not Stationary & 2.617346 & 0.0989 & 1 & I $(1)$ \\
PCAE & 3.2899 & 1 & Not Stationary & 6.251656 & 0 & 1 & I $(2)$ \\
PCE & 4.74455 & 1 & Not Stationary & 6.621602 & 0 & 1 & I $(2)$ \\
PE & 8.86481 & 1 & Not Stationary & 8.130316 & 0 & 1 & I $(2)$ \\
\hline
\end{tabular}

\subsection{Empirical Findings and Discussion}

\subsubsection{Empirical Findings}

The ADF result shows that the variables $\mathrm{Y}, \mathrm{K}$ and $\mathrm{L}$ contained unit roots when subjected to stationarity test at levels. After applying $1^{\text {st }}$ difference the variables became stationary and are therefore I(1) series. However, the public expenditure variables PCAE, PCE and PE were not stationary at $1^{\text {st }}$ difference after repeated lags until when we applied the $2^{\text {nd }}$ difference. Thus, the variables were confirmed as I(2) variables.

Since the variables are integrated at different levels, the conventional co-integration and the error correction techniques become inappropriate. We therefore re-specify Equations (8) and (9) in $1^{\text {st }}$ differenced log format as explained by Box and Jekins and thereafter estimate the models using the Ordinary Least Squares (OLS) technique to avoid spurious regression outcomes.

$$
\begin{gathered}
F D L Y_{t}=\beta_{0}+\beta_{1} F D L K_{t}+\beta_{2} F D L L_{t}+\beta_{3} F D L P E_{t}+\varepsilon_{t} \\
F D L Y_{t}=\beta_{0}+\beta_{1} F D L K_{t}+\beta_{2} F D L L_{t}+\beta_{3} F D L P C E_{t}+\beta_{4} F D L P C A E_{t} \varepsilon_{t}
\end{gathered}
$$

Where FDLY $_{\mathrm{t}}=$ First difference of the log of Gdp, FDLK $_{\mathrm{t}}=$ First difference of the $\log$ of capital, FDLL $_{\mathrm{t}}=$ First difference of the $\log$ of labour, FDLPE $=$ First difference of the $\log$ of public expenditure and $\mathrm{FDLPCE}_{\mathrm{t}}$ and $\mathrm{FDLPCAE}_{\mathrm{t}}$ are first difference of the log of public current expenditure and public capital expenditure respectively. $\beta_{0}-\beta_{4}$ are the parameters to be estimated and $\varepsilon_{t}$ is the error term. 
Table 2. Box Jekins O.L.S results (1970-2008)

\begin{tabular}{|c|c|c|c|c|}
\hline \multicolumn{5}{|c|}{ Model (10) Dependent Variable FDLY } \\
\hline Variables & Coeff & Std Error & T-value & Prob \\
\hline $\mathbf{C}$ & 11.2040 & 1.9960 & 5.6046 & 0.0000 \\
\hline FDLK & 0.2118 & 0.06314 & 3.3552 & 0.0020 \\
\hline FDLL & -0.3503 & 0.2164 & -1.6182 & 0.1151 \\
\hline FDLPE & 0.1294 & 0.0375 & 3.4428 & 0.0016 \\
\hline $\mathbf{A R}(\mathbf{1})$ & 3.59 & 1.58 & 2.2747 & 0.0295 \\
\hline \multicolumn{5}{|c|}{$\mathrm{R} 2=0.8995 ;$ F-stat $=73.87033 ;$ Prob $=0.0000$} \\
\hline \multicolumn{5}{|c|}{ Adjusted R2 $=0.8873 ;$ Dw $=2.052041$} \\
\hline \multicolumn{5}{|c|}{ Model (11) Dependent Variable FDLY } \\
\hline $\mathbf{C}$ & 8.9476 & 2.2305 & 4.0114 & 0.0003 \\
\hline FDLK & 0.2094 & 0.0728 & 2.8777 & 0.0071 \\
\hline FDLL & -0.0728 & 0.2341 & -0.3115 & 0.7577 \\
\hline FDLPCAE & 0.0271 & 0.0337 & 0.7202 & 0.4766 \\
\hline FDLPCE & 0.0570 & 0.0334 & 1.7015 & 0.0985 \\
\hline $\operatorname{AR}(\mathbf{1})$ & 3.50 & 2.00 & 1.753 & 0.0892 \\
\hline
\end{tabular}

$\mathrm{R} 2=0.8812 ;$ F-stat $=47.5105 ;$ Prob $=0.0000$

Adjusted R2 $=0.8627 ; \mathrm{Dw}=1.7136$

\subsection{Discussion of Findings}

Considering equation (10) from Table (2), it is evident that both capital (k) and public expenditure (pe) are correctly signed in line with a-priori expectation, but labour as an explanatory variable is not correctly signed. In the same vein, t-values of both capital and public expenditure were found to be significant at 1 percent while it is insignificant for labour. The Adjusted R2 of 0.8873 indicates that 88 percent variation in Gross domestic product (GDP) is responsible for jointly by the explanatory variables under consideration. F-statistics of 73.87033 is found to be significant at I percent and this shows that the model is of good fit. Also, Figure (1) shows that the residual is stationary around 0 i.e mean reverting. 


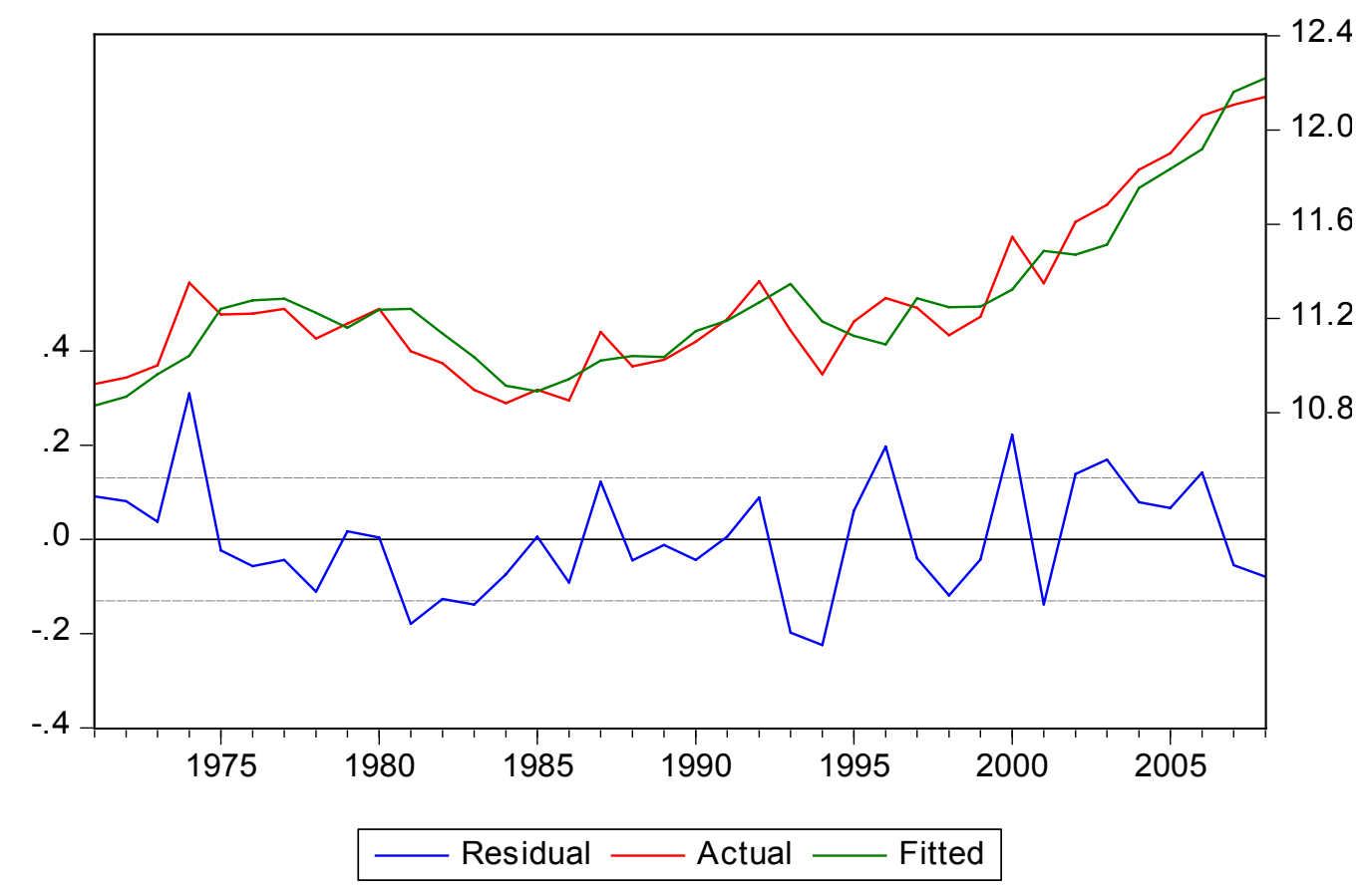

Figure 1. Residual, actual and fitted plots of public expenditure

The parsimonious regression result from the over-parameterized O.L.S results showed that the inclusion of the autoregressive model removed autocorrelation by increasing the DW to 2.05 and equally improving the performance of the parameter estimates.

Similarly for Equation (11), the split of public expenditure in two components - public current expenditure (PCE) and public capital expenditure (PCAE) reveals that both are correctly signed but insignificant at the conventional 5 percent level. Capital also conforms with the a-priori expectation and equally significant at both 1 and 5 percent levels of significance while labour remains not correctly signed and this time also insignificant. The F-statistics confirms the overall significance of the regression equation and the inclusion of the autoregressive term AR(1) in the model increase the DW to1.7136 thereby minimizing the autocorrelation problem.

\section{Conclusion and Policy Recommendations}

For quite some time, there has been a general belief that there exists an important relationship between public expenditure and economic performance. This is not surprising, since over time there has been a continuous interest in fiscal themes in most policy discussions. Public expenditure is one of the principles that can be used to measure the size of the government sector in an economy. Generally, the importance of the public sector lies in its expenditure. Over the year, total public expenditure has increased. Capital expenditure has risen and recurrent expenditure has followed the same trend. The study investigated the impact of public expenditure on economic growth using data for the period 1970 to 2008. The study revealed that public expenditure has a positive and significant impact on economic growth in Nigeria. The study also shows that capital expenditure has a positive impact on growth as well as recurrent expenditure. This called for effective management of public expenditure in 
Nigeria as continuous increase in public expenditure particularly public capital expenditure is what is needed to usher in the desired growth and development in Nigeria.

In the light of the findings which have emerged in the study, the following recommendations are advanced

a) There is the need for selectivity in choosing government investment programmes.

b) Since most government expenditures in Nigeria is unproductive, it is imperative that the government cuts down its expenditure, especially on activities that have no direct positive impact on output growth. Such government expenditures include construction of stadia, spending on West African Peace Keeping Missions as well as expenditures on social service activities.

c) Public expenditure should be used to tackle the problem of unemployment. We need some level of social and political stability if we are to pursue the goal of economic transformation.

d) Public expenditure should be used to bypass market mechanism in the distribution of goods and services. The market mechanism cannot effectively allocate societal resources there is need therefore to increase government participation in the economy through investments in public utilities and infrastructures.

\section{Acknowledgements}

We appreciate the contributions of Professor (Mrs) A. M. Osoba in proof-reading through the paper and also for her contribution when the paper was presented at the faculty seminar series.

The comments of Drs A. B Adesoye and A. O. B Sangosanya are equally appreciated in this respect.

\section{References}

Adamu, P. A. (2003). The Impact of Human Capital on Economic Growth in Nigeria: An Errorlcorrection Approach. Paper Presented at The 2002 Annual Conference of The Nigerian Economic Society, Nigeria

Adubi, A. A., \& Obioma, E. O. (1995). Public Expenditure in Nigeria, in Public Expenditure Management in Nigeria.

Barro, R. J. (1990). Government spending in a simple model of endogenous growth. Journal of Political Economy, 98(3). http://dx.doi.org/10.1086/261726

Buchanan, J., \& Tullock, C. (1961). Public Expenditure and Growth in the Economic Analysis of Government and Related Themes, Martin Robertson.

Deniz, Z., \& Dugruel, A. S. (2008). Disaggregated Education Data and Growth: Some Facts from Turkey and Mena Countries.

Junk, K., \& Vitali, K. (2008). Impact of Government Expenditure on Growth. Public Choice, 56, 193-200.

Lawal N. A., \& Wahab, T. I. (2011). Education and Economic Growth: The Nigerian Experience. Journal of Emerging Trends in Economics and Management Sciences (JETEMS), 2(3), 225-231.

Out, M. F., \& Adenuga, A. O. (2006). Economic Growth and Human Capital Bank of Nigeria, 
44(3).

Romer, D. (1996). Advanced Macroeconomics, McGraw-Hill Higher Education Publisher.

Schutlz, T. W. (1961). Investment in Human Capital. American Economic Review, 1-17.

Wiseman, J., \& Peakcock, A. T. (1958). The Growth of Public Expenditure in the United Kingdom, (pp. 1890-1955) Princeton University Press.

\section{Copyright Disclaimer}

Copyright reserved by the author(s).

This article is an open-access article distributed under the terms and conditions of the Creative Commons Attribution license (http://creativecommons.org/licenses/by/3.0/). 